Check for updates

Cite this: RSC Adv., 2017, 7, 36340

\title{
Novel synthesis of porous Mg scaffold as a reactive containment vessel for $\mathrm{LiBH}_{4}^{\dagger} \uparrow$
}

\author{
M. Veronica Sofianos, (D) *a Drew A. Sheppard, ${ }^{a}$ Matthew R. Rowles, (D) ${ }^{a}$

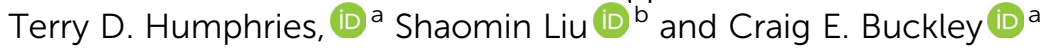

A novel porous $\mathrm{Mg}$ scaffold was synthesised and melt-infiltrated with $\mathrm{LiBH}_{4}$ to simultaneously act as both a confining framework and a destabilising agent for $\mathrm{H}_{2}$ release from $\mathrm{LiBH}_{4}$. This porous $\mathrm{Mg}$ scaffold was synthesised by sintering a pellet of $\mathrm{NaMgH}_{3}$ at $450{ }^{\circ} \mathrm{C}$ under dynamic vacuum. During the sintering process the multi-metal hydride, decomposed to $\mathrm{Mg}$ metal and molten $\mathrm{Na}$. The vacuum applied in combination with the applied sintering temperature, created the ideal conditions for the $\mathrm{Na}$ to vaporise and to gradually exit the pellet. The pores of the scaffold were created by the removal of the $\mathrm{H}_{2}$ and $\mathrm{Na}$ from the body of the $\mathrm{NaMgH}_{3}$ pellet. The specific surface area of the porous $\mathrm{Mg}$ scaffold was determined by the Brunauer-Emmett-Teller (BET) method and from Small-Angle X-ray Scattering (SAXS) measurements, which was 26(1) and 39(5) $\mathrm{m}^{2} \mathrm{~g}^{-1}$ respectively. The pore size distribution was analysed using the Barrett-Joyner-Halenda $(\mathrm{BJH})$ method which revealed that the majority of the pores were macropores, with only a small amount of mesopores present in the scaffold. The melt-infiltrated $\mathrm{LiBH}_{4}$ was highly dispersed in the porous scaffold according to the morphological observation carried out by a Scanning Electron Microscope (SEM) and also catalysed the formation of $\mathrm{MgH}_{2}$ as seen from the $\mathrm{X}$-ray diffraction (XRD) patterns of the samples after the infiltration process. Temperature Programmed Desorption (TPD) experiments, which were conducted under various $\mathrm{H}_{2}$ backpressures, revealed that the melt-infiltrated $\mathrm{LiBH}_{4}$ samples exhibited a $\mathrm{H}_{2}$ desorption onset temperature $\left(T_{\text {des }}\right)$ at $100{ }^{\circ} \mathrm{C}$ which is $250{ }^{\circ} \mathrm{C}$ lower than the bulk $\mathrm{LiBH}_{4}$ and $330{ }^{\circ} \mathrm{C}$ lower than the bulk $2 \mathrm{LiBH}_{4} / \mathrm{MgH}_{2}$ composite. Moreover, the $\mathrm{LiH}$ formed during the decomposition of the $\mathrm{LiBH}_{4}$ was itself observed to fully decompose at $550{ }^{\circ} \mathrm{C}$. The as-synthesised porous $\mathrm{Mg}$ scaffold acted as a reactive containment vessel for $\mathrm{LiBH}_{4}$ which not only confined the complex metal hydride but also destabilised it by significantly reducing the $\mathrm{H}_{2}$ desorption temperature down to $100{ }^{\circ} \mathrm{C}$.

rsc.li/rsc-advances

\section{Introduction}

Over the last few years metal hydrides and complex metal hydrides have been extensively investigated as hydrogen storage materials in order to be used in fuel cell technology, applied in transportation. ${ }^{\mathbf{1 - 4}} \mathrm{A}$ set of targets, determined by the U.S. Department of Energy suggests that a material system should contain at least $5.5 \mathrm{wt} \% \mathrm{H}_{2}$ to be deemed as suitable for application. ${ }^{5,6} \mathrm{LiBH}_{4}$ is one such material owing to its high theoretical gravimetric hydrogen storage density of $18.5 \mathrm{wt} \%$. $^{7}$ However, one of its greatest limitations as a prospective

${ }^{a}$ Hydrogen Storage Research Group, Fuels and Energy Technology Institute, Department of Physics and Astronomy, Curtin University, GPO Box U1987, Perth, WA 6845, Australia. E-mail: mvsofianou@gmail.com; Fax: +61 89266 2377; Tel: +61892661534

${ }^{b}$ Department of Chemical Engineering, Curtin University, GPO Box U1987, Perth, WA 6845, Australia

$\dagger$ Electronic supplementary information (ESI) available. See DOI: 10.1039/c7ra05275h hydrogen storage medium is that it decomposes at relatively high temperatures $\left(\sim 350{ }^{\circ} \mathrm{C}\right)$ according to eqn $(1) .^{8}$

$$
2 \mathrm{LiBH}_{4} \rightarrow 2 \mathrm{LiH}+2 \mathrm{~B}+3 \mathrm{H}_{2}
$$

The LiH decomposition product is extremely stable and does not decompose until at least $910{ }^{\circ} \mathrm{C}$ under 1 bar of $\mathrm{H}_{2}$ backpressure. ${ }^{9}$ Hence, $\mathrm{LiBH}_{4}$ when used at lower temperatures $(<910$ ${ }^{\circ} \mathrm{C}$ ) has a practical gravimetric hydrogen storage density of 13.8 wt $\%{ }^{10}$ Reversibility of $\mathrm{LiBH}_{4}$ is also problematic, as temperatures of above $600{ }^{\circ} \mathrm{C}$ and 350 bar of hydrogen pressure are required for reabsorption. ${ }^{\mathbf{1 1}}$ Overall, if the thermal stability and reversibility problems, were overcome, $\mathrm{LiBH}_{4}$ would be a very promising material.

A very common approach that has been extensively applied, in order to decrease the hydrogen desorption temperatures of $\mathrm{LiBH}_{4}$ is to thermodynamically destabilise it with a second phase such as $\mathrm{MgH}_{2}$ or $\mathrm{Mg} .{ }^{12-19}$ It is shown that when $\mathrm{MgH}_{2}$ or $\mathrm{Mg}$ is combined with $\mathrm{LiBH}_{4}$, a new decomposition pathway is created by forming $\mathrm{MgB}_{2}$ (eqn (2) and (3)). ${ }^{\mathbf{1 2}, 16}$ It has been proven 
that $\mathrm{MgB}_{2}$ is thermodynamically more stable in comparison to $\mathrm{Mg}$ or B and acts as the destabilising agent for the $2 \mathrm{LiBH}_{4}+$ $\mathrm{MgH}_{2}$ or $2 \mathrm{LiBH}_{4}+\mathrm{Mg}$ system. ${ }^{20}$

$$
\begin{aligned}
& 2 \mathrm{LiBH}_{4}+\mathrm{MgH}_{2} \rightarrow 2 \mathrm{LiBH}_{4}+\mathrm{Mg}+\mathrm{H}_{2} \rightarrow \\
& 2 \mathrm{LiH}+\mathrm{MgB}_{2}+4 \mathrm{H}_{2} \\
& 2 \mathrm{LiBH}_{4}+\mathrm{Mg} \rightarrow 2 \mathrm{LiH}+\mathrm{MgB}_{2}+3 \mathrm{H}_{2}
\end{aligned}
$$

When $\mathrm{MgH}_{2}$ is used as the second phase added to $\mathrm{LiBH}_{4}$, two chemical reactions are observed during desorption. First, $\mathrm{MgH}_{2}$ decomposes to $\mathrm{Mg}$ and then $\mathrm{LiBH}_{4}$ decomposes to form $\mathrm{LiH}$ and $\mathrm{MgB}_{2}$ as seen in eqn (2). The formation of $\mathrm{MgB}_{2}$ only depends on the reactivity between $\mathrm{B}$ and metallic $\mathrm{Mg}$, therefore a two reaction step always occurs. ${ }^{\mathbf{1 6}}$ Whereas, when $\mathrm{Mg}$ is used as a second phase, the decomposition pathway of $\mathrm{LiBH}_{4}$ occurs in one single chemical reaction (eqn (3)). These decomposition pathways can be manipulated according to the temperature and $\mathrm{H}_{2}$ backpressures applied during the temperature programmed desorption experiments. ${ }^{\mathbf{1 6}, \mathbf{1 7}}$

Additional studies have been conducted in order to further reduce the desorption temperature of hydrogen, hasten the kinetics and improve the reversibility of the $2 \mathrm{LiBH}_{4}-\mathrm{Mg}$ or $2 \mathrm{LiBH}_{4}-\mathrm{MgH}_{2}$ system by adding catalyst precursors such as metal salts, metal organic compounds or metal oxides. ${ }^{12,20,21}$

Another approach found in the literature, widely used in order to enhance the kinetics of the $2 \mathrm{LiBH}_{4}-\mathrm{MgH}_{2}$ system, is to nanoconfine the bulk composite into a porous scaffold. The reduction of the particle size down to the nanoscale ensures shorter diffusion distances for hydrogen and other light elements within the nanostructure. Hence, the hydrogen desorption and absorption rates improve in comparison to the bulk material. ${ }^{22-26}$

Even though many efforts have been made in order to reduce the $\mathrm{H}_{2}$ desorption temperature of the $2 \mathrm{LiBH}_{4}-\mathrm{Mg}$ and $2 \mathrm{LiBH}_{4}-$ $\mathrm{MgH}_{2}$ system, as demonstrated in the literature, no studies have reported any $\mathrm{H}_{2}$ desorption detected below $140{ }^{\circ} \mathrm{C}$ in these bulk or catalysed systems. Moreover, even though the nanoconfined as well as the catalysed nanoconfined $2 \mathrm{LiBH}_{4}-\mathrm{MgH}_{2}$ systems exhibited improved kinetics and reversibility in comparison to the bulk one, the values of the desorbed $\mathrm{H}_{2}\left(\mathrm{wt} \%\right.$ of $\left.\mathrm{H}_{2}\right)$ were poor and hence do not meet the targets set by the U.S. Department of Energy. ${ }^{6}$ Furthermore, the carbon aerogels used as scaffolds or activated carbons typically contain between 4 $\mathrm{wt} \%$ and $14 \mathrm{wt} \%$ of oxygen. ${ }^{27-29}$ Therefore, an oxidation reaction between the infiltrated metal hydride system and the oxygen from the scaffold is inevitable and causes $\mathrm{H}_{2}$ capacity loss of the complex metal hydride.

A new type of porous scaffolds have recently made a significant appearance in the literature called porous metal scaffolds. These type of scaffolds have been tested for battery, fuel-cell, energy and catalytic applications due to their robustness. ${ }^{30-33}$

In this study, we report a novel method for the synthesis of a porous $\mathrm{Mg}$ scaffold using $\mathrm{NaMgH}_{3}$ as a starting material. The hydride was pressed into a pellet and sintered under dynamic vacuum in order to remove $\mathrm{H}_{2}$ and $\mathrm{Na}$. The morphology of the $\mathrm{Mg}$ scaffold was investigated by $\mathrm{N}_{2}$ adsorption/desorption and
Small Angle X-ray scattering (SAXS) measurements as well as by a Scanning Electron Microscope (SEM) which revealed an open pore network that consisted mainly of macropores and only a small number of mesopores. $\mathrm{LiBH}_{4}$ was melt-infiltrated into the porous metal scaffold and catalysed the formation of $\mathrm{MgH}_{2}$ as seen from the X-ray diffraction patterns of the melt-infiltrated samples. Scanning Electron Microscopy revealed that the meltinfiltrated $\mathrm{LiBH}_{4}$ was highly dispersed. All melt-infiltrated samples exhibited a $\mathrm{H}_{2}$ desorption onset temperature $\left(T_{\mathrm{des}}\right)$ at $100{ }^{\circ} \mathrm{C}$ which is $250{ }^{\circ} \mathrm{C}$ lower than the bulk $\mathrm{LiBH}_{4}$ and $330{ }^{\circ} \mathrm{C}$ lower than the bulk $2 \mathrm{LiBH}_{4} / \mathrm{MgH}_{2}$ composite. Furthermore, the $\mathrm{LiBH}_{4}$ of the melt-infiltrated samples was completely decomposed at $550{ }^{\circ} \mathrm{C}$ (under 1.5-2.7 bar of $\mathrm{H}_{2}$ backpressure) showing no $\mathrm{LiH}$ present in the samples even though $\mathrm{LiH}$ is known to decompose above $910{ }^{\circ} \mathrm{C}$ under 1 bar of $\mathrm{H}_{2}$ backpressure or completely decompose to form LiMg alloys when vacuum is applied at $560{ }^{\circ} \mathrm{C}$. The porous $\mathrm{Mg}$ scaffold acted as a reactive containment vessel for $\mathrm{LiBH}_{4}$ by simultaneously destabilising and confining it. These novel hydrogen storage composite materials exhibited both low $\mathrm{H}_{2}$ desorption temperatures and high values of experimental desorbed $\mathrm{H}_{2}$ which make them promising candidates for on-board hydrogen storage in vehicles run by a fuel cells.

\section{Experimental details}

\subsection{Sample preparation}

All chemicals used for the synthesis were sensitive to both air and moisture. Therefore, all sample preparation and handling was performed using an Ar glovebox with $\mathrm{O}_{2}$ and $\mathrm{H}_{2} \mathrm{O}$ less than 1 ppm to avoid sample contamination.

$\mathrm{NaMgH}_{3}$ was synthesised by ball milling $\mathrm{NaH}$ (Sigma Aldrich, 95\%) and $\mathrm{MgH}_{2}$ (Alfa Aesar, 98\%) in a 1 : 1 molar ratio under an Ar atmosphere at room temperature using an Across International Planetary Ball Mill (PQ-N04) employing stainless steel vials. A ball to powder mass ratio of $30: 1$ was applied by using the same number of $10 \mathrm{~mm}$ and $6 \mathrm{~mm}$ diameter stainless steel balls. The rotational speed was $350 \mathrm{rpm}$ with a total milling time of 4 hours. The vials changed rotation every $15 \mathrm{~min}$ with a 5 min pause between each rotation. The final product was then annealed overnight at $300{ }^{\circ} \mathrm{C}$ under 50 bar of $\mathrm{H}_{2}$.

The porous $\mathrm{Mg}$ scaffold was synthesised by pressing $\mathrm{NaMgH}_{3}$ into a pellet using an $8 \mathrm{~mm}$ stainless steel die under a 2.5 ton load. The $\mathrm{NaMgH}_{3}$ was loaded into the die inside the glovebox and then placed into a sealable plastic bag that was connected, via plastic tubing, to a push-fit valve. The bag was then removed from the glovebox and connect to vacuum before pressing. The resulting pellets were typically pressed to $70 \%$ of the crystal density of $\mathrm{NaMgH}_{3}$, were $\sim 1 \mathrm{~mm}$ in height and weighed $0.1 \mathrm{~g}$. After disconnecting the vacuum line, the die was immediately returned to the glovebox where the pellets were removed from the die and transferred to steel sample cells and lastly sintered for 3 hours under dynamic vacuum at $450{ }^{\circ} \mathrm{C}$ using a Labec VTF 80/12 tube furnace. The ramping rate applied was $5{ }^{\circ} \mathrm{C} \min ^{-1}$ and after the 3 hours of sintering time the sample was left to cool to room temperature. After removal of $\mathrm{Na}$ and $\mathrm{H}_{2}$ by the sintering process, all pellets retained the 
shape and size of the initial $\mathrm{NaMgH}_{3}$ pellet. Using an initial $\mathrm{H}_{2}$ backpressure of $\sim 60$ bar to prevent decomposition, various weight percentages of $\mathrm{LiBH}_{4}$ (Sigma Aldrich $\geq 90 \%$ ) were meltinfiltrated into the porous $\mathrm{Mg}$ scaffold using a stainless steel reactor heated to $300{ }^{\circ} \mathrm{C}\left(\Delta T=5{ }^{\circ} \mathrm{C} \mathrm{min}{ }^{-1}\right)$. The samples were held at $300{ }^{\circ} \mathrm{C}$ for 30 minutes with a final backpressure of $\mathrm{H}_{2}$ in the reactor reaching $\sim 70$ bar $\mathrm{H}_{2}$. The samples were then cooled to room temperature. In total, six different weight percentages of $\mathrm{LiBH}_{4}(12.78,22.50,26.13,32.55,33.95$ and $35.05 \mathrm{wt} \%)$ were melt-infiltrated into the porous $\mathrm{Mg}$ scaffolds. All samples were in a pellet form unless described otherwise. Bulk $\mathrm{LiBH}_{4}$ and $\mathrm{LiBH}_{4} / \mathrm{MgH}_{2}$ with a 2:1 molar ratio were used as reference materials. The bulk $\mathrm{LiBH}_{4} / \mathrm{MgH}_{2}$ powder was prepared by ball milling $\mathrm{LiBH}_{4}$ and $\mathrm{MgH}_{2}$ using identical experimental milling conditions as previously mentioned (Table 1 ).

\subsection{Sample characterisation}

Powder X-ray diffraction (XRD) was used for the phase analysis and phase observations of all samples utilising a Bruker D8 Advanced diffractometer with $\mathrm{CuK}_{\alpha}$ radiation. The measured $2 \theta$ range $\left(15-80^{\circ}\right)$ was scanned using a $0.03^{\circ}$ step size at $1.6 \mathrm{~s}$ per step, a rotational speed of $30 \mathrm{rpm}$ and a $0.3^{\circ}$ divergence slit. The accelerating voltage and applied current were $40 \mathrm{kV}$ and $40 \mathrm{~mA}$, respectively. Phase identification was accomplished by the EVA software (by Bruker) that uses as a database the Powder Diffraction Files (PDF) cards of the International Centre for Diffraction Data. The low background Si wafer XRD sample holders used were covered with a poly(methylmethacrylate) (PMMA) airtight hemispherical dome to prevent oxygen/ moisture contamination during data collection. The PMMA airtight dome results in a broad hump in XRD patterns centred at $\sim 20^{\circ} 2 \theta$. Due to the specimen mounting, all samples are $\sim 1$ $\mathrm{mm}$ higher than the centre of the goniometer, resulting in a $2 \theta$ offset to all peak positions. In order to investigate the formation of $\mathrm{MgB}_{2}$ in the infiltrated samples, Rietveld refinement was conducted using TOPAS Ver.5. ${ }^{34,35}$

The specific surface area and the porosity of the $\mathrm{Mg}$ scaffold was analysed by nitrogen $\left(\mathrm{N}_{2}\right)$ adsorption/desorption measurements performed at $77 \mathrm{~K}$ using a Micromeritics ASAP 3020 system (Micromeritics, Nor-cross, GA, USA). The specific surface area of the scaffold was calculated from the $\mathrm{N}_{2}$ adsorption data,

Table 1 Description of all samples

\begin{tabular}{|c|c|}
\hline Description & Sample ID \\
\hline Porous $\mathrm{Mg}+12.78 \mathrm{wt} \% \mathrm{LiBH}_{4}$ & PMg13 \\
\hline Porous $\mathrm{Mg}+22.50 \mathrm{wt} \% \mathrm{LiBH}_{4}$ & PMg23 \\
\hline Porous $\mathrm{Mg}+26.13 \mathrm{wt} \% \mathrm{LiBH}_{4}$ & PMg26 \\
\hline Porous $\mathrm{Mg}+32.55$ wt $\% \mathrm{LiBH}_{4}$ & PMg33 \\
\hline Porous $\mathrm{Mg}+33.95$ wt $\% \mathrm{LiBH}_{4}$ & PMg34 \\
\hline Porous $\mathrm{Mg}+35.05 \mathrm{wt} \% \mathrm{LiBH}_{4}$ & PMg35 \\
\hline Bulk $2 \mathrm{LiBH}_{4}: \mathrm{MgH}_{2}$ molar ratio pellet form & Bulk pellet \\
\hline Bulk $2 \mathrm{LiBH}_{4}: \mathrm{MgH}_{2}$ molar ratio powder form & Bulk powder \\
\hline $\begin{array}{l}\text { Porous } \mathrm{Mg} \text { crushed then melt-infiltrated with } \\
2 \mathrm{LiBH}_{4}: \mathrm{Mg} \text { molar ratio }\end{array}$ & Bulk Mg:2 $\mathrm{LiBH}_{4}$ \\
\hline 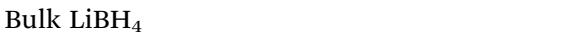 & 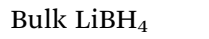 \\
\hline
\end{tabular}

at relative pressures between 0.05 and 0.30 , by employing the Brunauer-Emmett-Teller (BET) multi-point method. ${ }^{36}$ The pore size distributions and volumes in the macro- $(>50 \mathrm{~nm})$ and meso-range (2-50 $\mathrm{nm}$ ) were calculated using the Barrett-Joyner-Halenda (BJH) method from the desorption branch of the isotherm. $^{37}$

The specific surface area was also investigated by SmallAngle X-ray Scattering (SAXS) with measurements conducted at the Australian Synchrotron. The measured intensities were put onto an absolute scale by use of a glassy carbon standard, scaled by the specimen thickness, ${ }^{38}$ and an empty capillary subtracted as background. The scattering pattern was modelled with the unified model $^{39}$ in Irena, ${ }^{40}$ and the Porod $^{40}$ slope extracted for the low and mid- $q$ regions. The unified model is applied in order to describe scattering from complex systems that contain multiple levels of related structural features. The extracted Porod slope for the low and mid- $q$ regions provides information about the size and shape of the scattering particles, in this case the pores and their correlations. The specific surface area, $\sigma(r)$, was calculated following the approach of Hurd (eqn (4)) with the size of the probe used $(r)$ was $21 \AA^{41}{ }^{41}$ This value of $r$ is the transition size for surface fractals to Porod scattering. ${ }^{42}$

$$
\sigma(r)=\frac{S(r)}{V \rho_{0}}=\sigma_{x} r^{2-D}
$$

$S(r)$ is the area of fractal surface and is equal to $S(r)=S_{x} r^{2-D}$, where $S_{x}$ is a sample-dependent prefactor, $D$ is the surface fractal dimension, $V$ is the volume under consideration and $\rho_{0}$ is the density of the Mg.

$\sigma_{x}$ which was calculated using eqn (5), as seen bellow.

$$
\sigma_{x}=\frac{\lim _{q \rightarrow \infty}\left[q^{6-D} I(q)\right]}{\pi F(D)(\Delta \rho)^{2} \rho_{0}}
$$

where, $q$ is the scattering vector, $q=(4 \pi / \lambda) \sin (\theta / 2)(\lambda$ is the wavelength of the radiation in the scattering medium and $\theta$ is the scattering angle), $\lim ($ ) denotes the largest $q$ limit and $F(D)$ $=\{\Gamma(5-D) \sin [(3-D) \pi / 2]\} /(3-D)$, where $\Gamma$ is the gamma function.

Morphological observations were carried out with a Zeiss Neon 40EsB (Zeiss, Germany) scanning electron microscope (SEM). Specimens were prepared by placing an extracted piece from the inner centre of the pellet onto carbon tape before coating them with a $3 \mathrm{~nm}$ layer of platinum to produce a conductive layer and reduce charging during SEM data collection. The exposure of the samples to air was minimised by using a custom made ante chamber in which the specimens were transferred from the glovebox to the coating instrument and then to the SEM chamber.

Temperature Programmed Desorption (TPD) measurements were undertaken on a computer controlled Sieverts/volumetric apparatus. ${ }^{43}$ The sample temperature and pressure was recorded every $30 \mathrm{~s}$ using a K-type thermocouple with a calibrated accuracy of $0.1{ }^{\circ} \mathrm{C}$ at $419{ }^{\circ} \mathrm{C}$ and a digital pressure transducer (Rosemount 3051S) with a precision/accuracy of 14 mbar. Hydrogen desorption data was obtained in the temperature 
range from room temperature to $550{ }^{\circ} \mathrm{C}$ with a ramping rate of $5{ }^{\circ} \mathrm{C} \min ^{-1}$. The temperature was then kept isothermal at $550{ }^{\circ} \mathrm{C}$ for 4 hours. Four TPD measurements were applied for the $\mathrm{LiBH}_{4}$ melt-infiltrated samples under $0,1,2$ and 3.4 bar of $\mathrm{H}_{2}$ backpressure, respectively. Whereas, TPD experiments for the bulk samples were applied under 0 bar of $\mathrm{H}_{2}$ backpressure.

\section{Results and discussion}

\subsection{Initial phase analysis}

The X-ray diffraction pattern of the as-prepared porous $\mathrm{Mg}$ scaffold is presented in Fig. 1(a). It can be seen that the $\mathrm{NaMgH}_{3}$ was completely decomposed to $\mathrm{Mg}$ (JCPD 35-0821) after the sintering process. According to the literature $\mathrm{NaMgH}_{3}$ decomposes in two reaction steps as presented below. ${ }^{\mathbf{4 4 - 4 8}}$

$$
\begin{gathered}
\mathrm{NaMgH}_{3} \rightarrow \mathrm{NaH}+\mathrm{Mg}+\mathrm{H}_{2} \\
\mathrm{NaH}+\mathrm{Mg} \rightarrow \mathrm{Na}(\mathrm{l})+\mathrm{Mg}+\frac{1}{2} \mathrm{H}_{2}
\end{gathered}
$$

The first reaction step (eqn (6)) takes place at $371^{\circ} \mathrm{C}$ at $1 \mathrm{bar}$ of $\mathrm{H}_{2}$ back pressure. ${ }^{48}$ It is expected that when dynamic vacuum is applied, this reaction will take place at lower temperature than $371^{\circ} \mathrm{C}$. According to the literature eqn (7) occurs at $427^{\circ} \mathrm{C}$ at 1 bar of $\mathrm{H}_{2}$ back pressure ${ }^{48}$ in which $\mathrm{NaH}$ decomposes to $\mathrm{Na}$ metal and $\mathrm{H}_{2}$ (eqn (5)). ${ }^{4-53} \mathrm{Na}$ has a vapour pressure of $0.001 \mathrm{bar}$ when it is in a molten state at $450{ }^{\circ} \mathrm{C} .^{54,55}$ Hence, the vacuum applied during the sintering process, $\sim 1.33 \times 10^{-5}$ bar, was low enough in order for the molten $\mathrm{Na}$ to be vaporised and removed from the main body of the pellet. The Na vapour was then captured in a cooler part of the reactor with steel wool.

The mass of the pellet on average after sintering was $1.9 \%$ higher than the theoretical value calculated by assuming the $\mathrm{Na}$ and $\mathrm{H}_{2}$ were completely removed from the initial $\mathrm{NaMgH}_{3}$ pellet. This difference in the mass values may be due to the fact

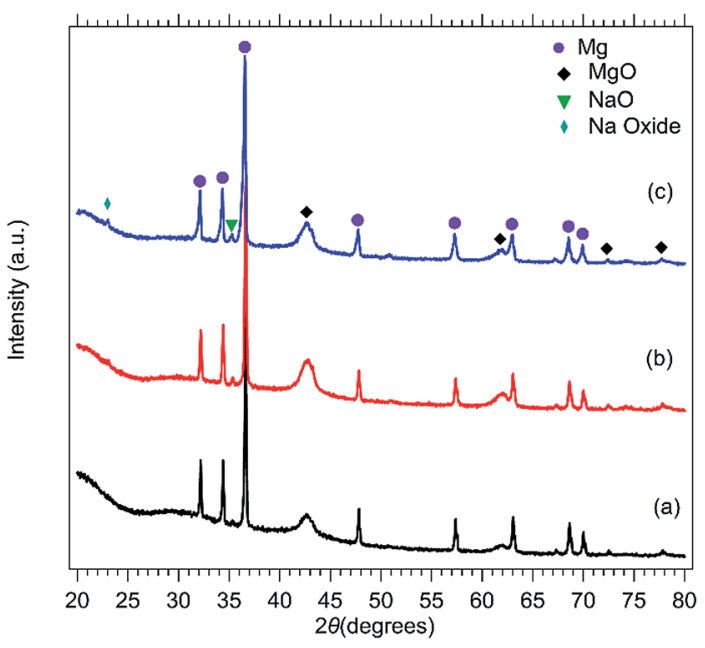

Fig. 1 XRD patterns of (a) the as-prepared porous Mg scaffold, (b) porous Mg scaffold after blank infiltration, (c) crushed porous Mg scaffold after blank infiltration. that the molten $\mathrm{Na}$ was not entirely removed from the initial pellet, even though diffraction peaks attributable to metallic $\mathrm{Na}$ are not present in Fig. 1 or due to the fact that the sample is not entirely pure as the starting material $\left(\mathrm{NaMgH}_{3}\right)$ contains impurities. The non-presence of $\mathrm{Na}$ peaks in Fig. 1 may be due to the fact that it is in low quantity, therefore not detectable by $\mathrm{X}$-ray diffraction or/and it is in a nanocrystalline phase. The broad peaks that correspond to $\mathrm{MgO}$ (JCPD 45-0946) are due to the impurities from the starting material. ${ }^{44}$

An obvious concern was that the porous $\mathrm{Mg}$ will form $\mathrm{MgH}_{2}$ under the temperature and $\mathrm{H}_{2}$ pressure required for the meltinfiltration of $\mathrm{LiBH}_{4}$. Thus, in order to confirm that the porous $\mathrm{Mg}$ scaffold will not form $\mathrm{MgH}_{2}$ while the melt-infiltration conditions of $\mathrm{LiBH}_{4}$ are applied $\left(300{ }^{\circ} \mathrm{C}\right.$, initial 60 bar $\left.\mathrm{H}_{2}\right)$, a blank infiltration test was carried out. The diffraction pattern of the porous $\mathrm{Mg}$ scaffold after the blank infiltration is presented in Fig. 1(b). No diffraction peaks of $\mathrm{MgH}_{2}$ were present. In order to further investigate that there is no formation of $\mathrm{MgH}_{2}$ also in the inner parts of the porous $\mathrm{Mg}$ scaffold away from its surface, the sample was crushed into a powder and further analysed (Fig. 1(c)). No diffraction peaks of $\mathrm{MgH}_{2}$ were present in this pattern either. According to Bogdanović et al. in order to rehydrogenate a sintered $\mathrm{Mg}$ sample, high temperatures (450-500 ${ }^{\circ} \mathrm{C}$ ) and pressures (100-110 bar $\mathrm{H}_{2}$ ) are required. ${ }^{56}$ Thus, the infiltration conditions applied did not kinetically favour the formation of $\mathrm{MgH}_{2}$. Moreover, the formation of $\mathrm{MgH}_{2}$ would have resulted in a volume expansion of the $\mathrm{Mg}$ pellet due to its transformation to $\mathrm{MgH}_{2}$. This would have resulted in the disintegration/decrepitation of the porous $\mathrm{Mg}$ scaffold. Such observation was not noted after the blank infiltration test. Therefore, the structural integrity of the porous $\mathrm{Mg}$ scaffold acted as an initial confirmation of the non-formation of $\mathrm{MgH}_{2}$. Diffraction peaks that correspond to $\mathrm{Na}$ oxide and $\mathrm{NaOH}$ (JCPD 01-075-0642) which are present in both patterns Fig. 1(b and c) are impurities from the starting material $\left(\mathrm{NaMgH}_{3}\right) .{ }^{\mathbf{4 4}}$

Fig. 2 shows the diffraction patterns of the melt-infiltrated samples in a pellet form with different wt\% of $\mathrm{LiBH}_{4}$. Fig. 2(a

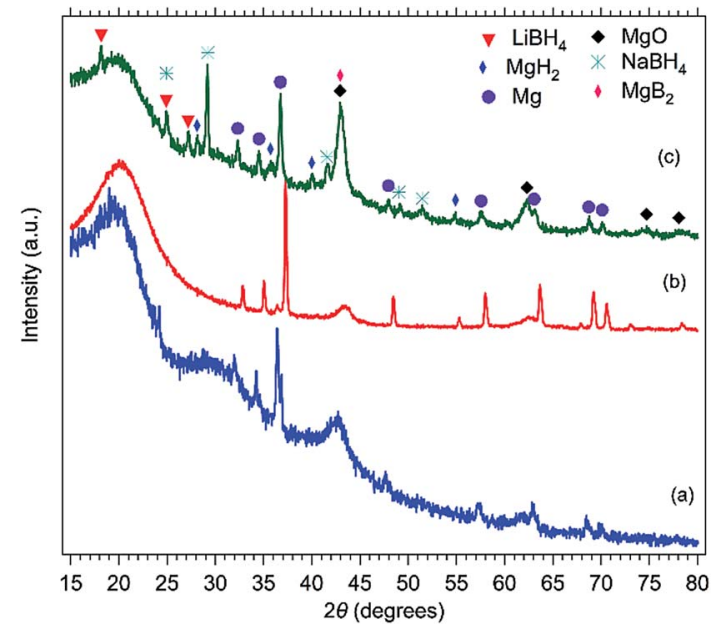

Fig. 2 XRD patterns of (a) PMg13, (b) PMg23 and (c) PMg33. All samples were measured as pellets. 
and b) represent the diffraction pattern of a pellet with 12.78 and $22.50 \mathrm{wt} \%$ of infiltrated $\mathrm{LiBH}_{4}$ respectively. Only peaks that correspond to $\mathrm{Mg}$ and $\mathrm{MgO}$ are present in Fig. 2(a). The lack of $\mathrm{LiBH}_{4}$ peaks in both Fig. 2(a) and (b) indicates that the complex metal hydride has penetrated the surface of the scaffold during the infiltration process and has occupied the inner pores of the scaffold or that if it is present at the surface of the pellet that it is either amorphous or nanocrystalline. In Fig. 2(b) small diffraction peaks of $\mathrm{MgH}_{2}$ are present. The XRD pattern of the sample with the highest wt\% of infiltrated $\mathrm{LiBH}_{4}$ (32.55 wt\%) exhibits diffraction peaks that correspond to $\mathrm{LiBH}_{4}$ (JCPD 04-011-3748), $\mathrm{NaBH}_{4}\left(\mathrm{JCPD}\right.$ 04-012-3346), $\mathrm{MgH}_{2}$ (JCPD 12-0697) and $\mathrm{MgB}_{2}$ (JCPD 04-010-6469). The $\mathrm{LiBH}_{4}$ that has been infiltrated in this sample is close to the maximum amount that can be infiltrated (35.68 wt\% of $\mathrm{LiBH}_{4}$ ) without exceeding the pore volume of the scaffold, (the value of which is mentioned in the pore analysis section of the manuscript). Thus, the concentration of $\mathrm{LiBH}_{4}$ is high enough at the surface to be observed with X-ray diffraction. The formation of $\mathrm{NaBH}_{4}$ is due to the partial reaction of residual Na with the $\mathrm{LiBH}_{4}$ at high temperatures. ${ }^{57} \mathrm{MgB}_{2}$ is present either due to the partly decomposition of the complex metal hydride during the infiltration process, even though the appropriate pressure of $\mathrm{H}_{2}$ was applied, in order to avoid the decomposition reaction, or that the $\mathrm{H}_{2}$ backpressure was not high enough to stop the reaction between $\mathrm{LiBH}_{4}$ and $\mathrm{Mg}$ to form $\mathrm{MgB}_{2}$. Lastly, even though there was no $\mathrm{MgH}_{2}$ formation observed during the blank infiltration process of the $\mathrm{Mg}$ scaffold, $\mathrm{MgH}_{2}$ is present in Fig. 2(c). This comes in contrast to the previous observation, suggesting that $\mathrm{LiBH}_{4}$ acts as a catalyst for the formation of $\mathrm{MgH}_{2}$ during the melt-infiltration process.

In order to compare the surface composition of the infiltrated pellets with their interior, XRD patterns were obtained from the same samples after they were crushed into a powder (Fig. 3). The XRD pattern of PMg13, Fig. 3(a), shows only Mg and $\mathrm{MgO}$ diffraction peaks as the amount of infiltrated $\mathrm{LiBH}_{4}(12.78$ $\mathrm{wt} \%$ ) and its low X-ray scattering power make it difficult to detect. Diffraction peaks of $\mathrm{LiBH}_{4}, \mathrm{MgH}_{2}$, and $\mathrm{NaBH}_{4}$ are present in samples PMg23 and PMg33 (Fig. 3(a and b)). The XRD pattern of the crushed sample PMg33 has been analysed by the Rietveld refinement method in order to investigate the formation of $\mathrm{MgB}_{2}$, as $\mathrm{MgO}$ and $\mathrm{MgB}_{2}$ have overlapping peaks at $2 \theta$ equal to $\sim 43^{\circ}$ (Fig. $\mathrm{S} 1 \dagger$ ). Moreover, in order to investigate the formation of $\mathrm{MgH}_{2}$ of the melt-infiltrated samples, an X-ray diffraction pattern (Fig. 3(d)) of a crushed $\mathrm{Mg}$ pellet that was melt-infiltrated (at $300{ }^{\circ} \mathrm{C}$ under 60 bar $\mathrm{H}_{2}$ ) with $\mathrm{LiBH}_{4}$ in a $2: 1$ molar ratio of $\mathrm{LiBH}_{4}: \mathrm{Mg}$ was obtained. Diffraction peaks of $\mathrm{LiBH}_{4}$ and $\mathrm{NaBH}_{4}$ are present in this particular sample (Fig. 3(d)) but no formation of $\mathrm{MgH}_{2}$ is evident in the same sample. This observation implies that the formation of $\mathrm{MgH}_{2}$ only occurs due to the intimate contact between porous $\mathrm{Mg}$ and the infiltrated $\mathrm{LiBH}_{4}$ and that a $2: 1$ molar ratio of $\mathrm{LiBH}_{4}: \mathrm{Mg}$ is insufficient for $\mathrm{LiBH}_{4}$ to act as a catalyst for the hydriding of $\mathrm{Mg}$.

\subsection{Pore analysis of $\mathrm{Mg}$ scaffold}

The $\mathrm{N}_{2}$ adsorption/desorption isotherms of the as-prepared porous $\mathrm{Mg}$ scaffold is presented in Fig. 4(a). The isotherms

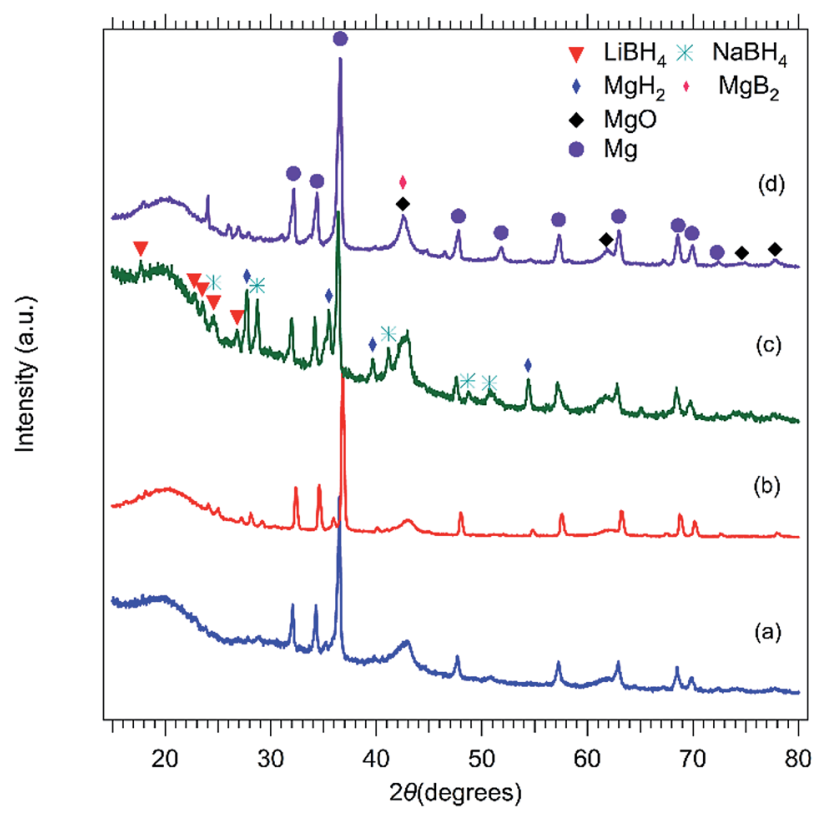

Fig. 3 XRD patterns of (a) PMg13, (b) PMg23, (c) PMg33 and (d) bulk $2 \mathrm{LiBH}_{4} / \mathrm{Mg}$. All (a) to (c) samples have been crushed into a powder form.

belong to a type II with a H3 type hysteresis loop which is associated with samples having large mesoporous and macroporous. ${ }^{58}$ The isotherms show no knee at low relative pressures that indicates an extremely weak adsorbate-adsorbent interaction that is representative for samples with no micropores present. In Fig. 4(c) the pore size distribution of the scaffold is presented. It can be seen that the pores present in the scaffold are polydisperse. This observation is in agreement with the SEM micrographs (Fig. 6(a and b)) and the possible reasons for this existing variability is mentioned in more details in the SEM section of this manuscript. It is noticeable that pores with diameters ranging from 1.7 to $3.6 \mathrm{~nm}$ form the larger proportion, whereas larger pores ranging between $28-45 \mathrm{~nm}$ in diameter have a smaller proportion in the scaffold as a whole. The total pore volume of the scaffold is $1.25 \mathrm{~cm}^{3} \mathrm{~g}^{-1}$, including the volume of the voids which were created during the compaction of the starting powder $\left(\mathrm{NaMgH}_{3}\right)$ into a pellet and it is equal to $\sim 0.42$ $\mathrm{cm}^{3} \mathrm{~g}^{-1}$. This volume was calculated using the crystal density of $\mathrm{NaMgH}_{3}$ and also the physical (bulk) density of the pellet derived from its physical dimensions. The volume due to the micropores and mesopores with diameter within the range of $1.7-48 \mathrm{~nm}$ as calculated from the $\mathrm{BJH}$ method (Table 2) is equal to $0.06 \mathrm{~cm}^{3}$ $\mathrm{g}^{-1}$. Finally, the remaining volume is due to the macropores greater than $50 \mathrm{~nm}$ in size which are present in the scaffold. The BET surface area of the scaffold is 26.05(1) $\mathrm{m}^{2} \mathrm{~g}^{-1}$.

According to SAXS analysis, the average Porod slope in the low and mid $q$ ranges was 3.31, indicating that the pores in the pellet formed a surface fractal (Fig. 5(a)). The surface fractal dimension was $D=2.69$ and $r=21 \AA$. The value of $r(r=2 \pi / q)$ was calculated using $q=0.31 \AA^{-1}$, which is the value for the transition from power-law 3.31 to 4 . A plot of $I q^{3.31} v s$. $q$, shown in Fig. 5(b), shows a plateau at $q=0.21 \AA^{-1}$, with 

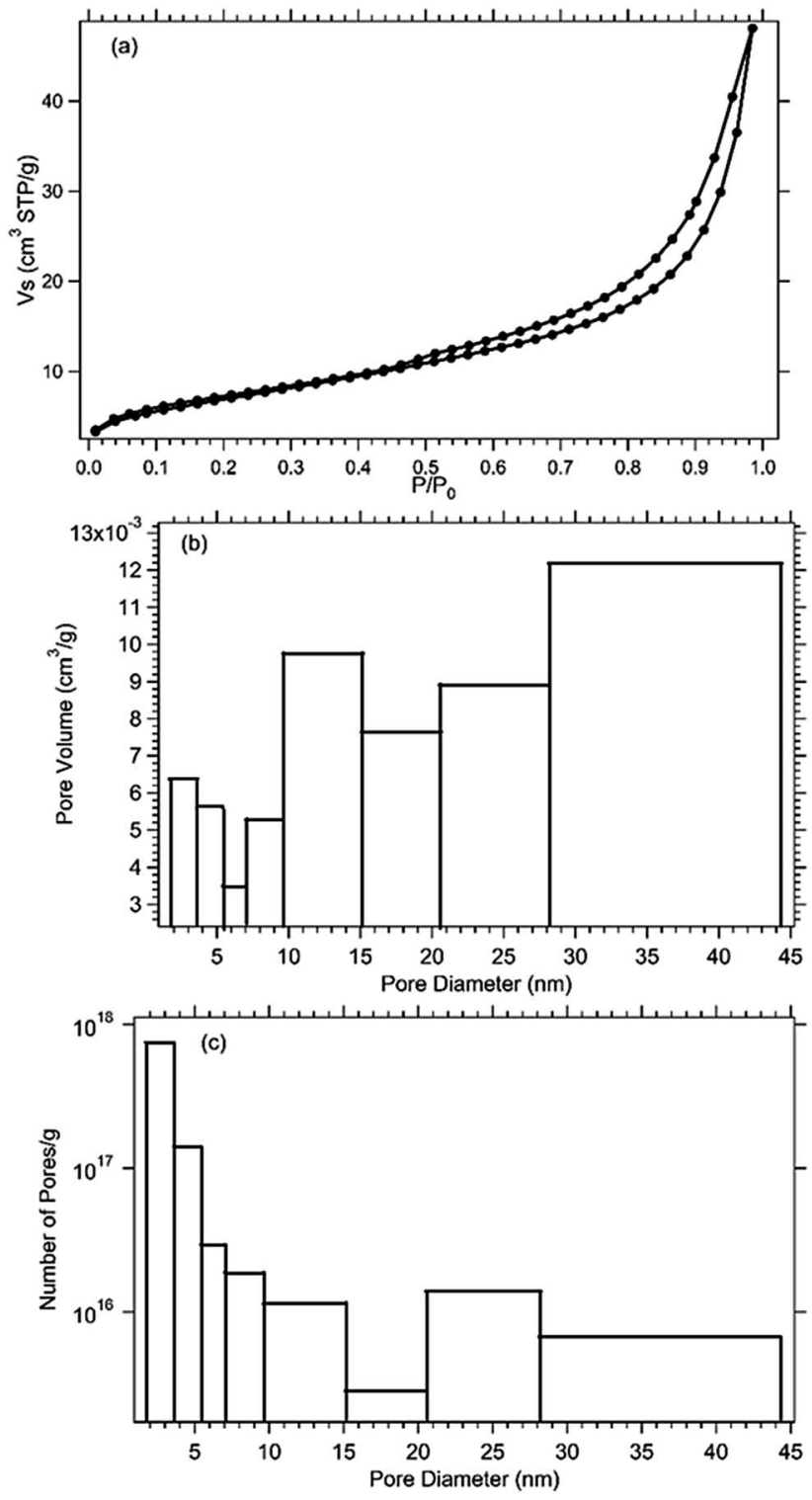

Fig. 4 (a) $\mathrm{N}_{2}$ adsorption/desorption isotherm (b) pore volume distribution diagram and (c) pore size distribution diagram of the of the porous Mg scaffold.

$\lim \left(I q^{3.31}\right)=2.06 \times 10^{24} \mathrm{~cm}^{-4.31} \cdot F(D)$ was equal to $1.77,(\Delta \rho)^{2}$ was equal to $2.13 \times 10^{22} \mathrm{~cm}^{-4}$ and $\rho_{0}$ was equal to the crystal density of $\mathrm{Mg}$ that is $1.75 \mathrm{~g} \mathrm{~cm}^{-3}$. Substituting these values into the equation of Hurd $^{41}$ (eqn (4)) to allow for a direct comparison with the BET results, yields a specific surface area of $39(5) \mathrm{m}^{2}$ $\mathrm{g}^{-1}$. This value was observed to be larger than the BET value, as this surface area also includes closed porosity.
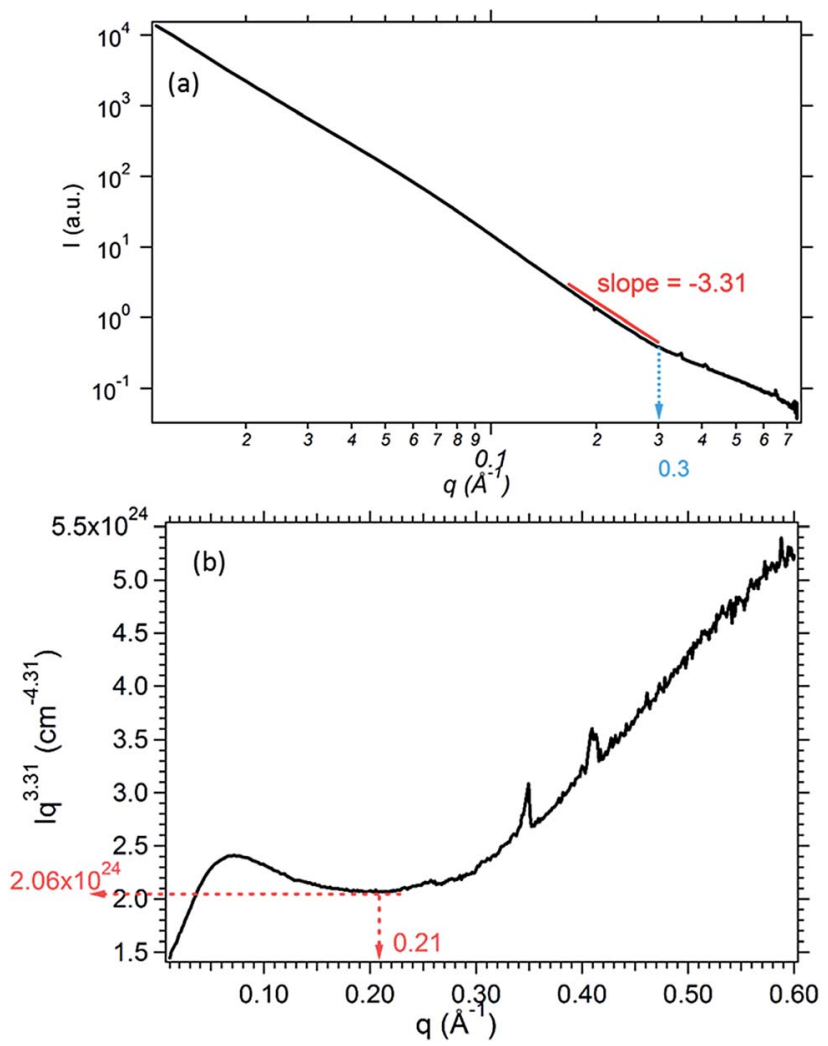

Fig. 5 SAXS data plotted (a) $\log (/)$ versus $\log (q)$ and (b) $/ q^{3.31}$ versus $q$ of the porous $\mathrm{Mg}$ scaffold after $3 \mathrm{~h}$ of sintering at $450{ }^{\circ} \mathrm{C}$ under dynamic vacuum.

The SEM micrographs of the as-prepared porous Mg scaffold are presented in Fig. 6(a and b). The pores have a broad range of sizes and are mainly macropores. This observation was also confirmed by the $\mathrm{N}_{2}$ adsorption/desorption isotherms and the applied BJH method of this particular sample. The $\mathrm{Mg}$ scaffold has an open porous network structure similar to a sponge. The walls of the solid $\mathrm{Mg}$ that form the pores are thin which makes it easier for the $\mathrm{H}_{2}$ to diffuse through them when the pores are occupied with $\mathrm{LiBH}_{4}$ during its thermal decomposition. The voids $(1-2 \mu \mathrm{m})$, have been created during the compaction of the $\mathrm{NaMgH}_{3}$ powder into a pellet. The macropores present in the scaffold may have been created from the molten sodium evaporating due to the applied dynamic vacuum during the sintering process. Finally, the mesopores present in the scaffold may have been formed during the desorption of $\mathrm{H}_{2}$ while the $\mathrm{NaMgH}_{3}$ pellet was heated under dynamic vacuum. The small number of mesopores may in part, be due to the fact that the $\mathrm{H}_{2}$ is diffused

Table 2 Physical properties of porous Mg scaffold

\begin{tabular}{llllll}
\hline & $\begin{array}{l}\text { Specific surface } \\
\text { area (BET) } \\
\left(\mathrm{m}^{2} \mathrm{~g}^{-1}\right)\end{array}$ & $\begin{array}{l}\text { Specific surface } \\
\text { area (SAXS) } \\
\left(\mathrm{m}^{2} \mathrm{~g}^{-1}\right)\end{array}$ & $\begin{array}{l}\text { Pore volume due } \\
\text { to mesopores } \\
\left(\mathrm{cm}^{3} \mathrm{~g}^{-1}\right)\end{array}$ & $\begin{array}{l}\text { Pore volume due } \\
\text { to macropores } \\
\left(\mathrm{cm}^{3} \mathrm{~g}^{-1}\right)\end{array}$ & $\begin{array}{l}\text { Pore volume } \\
\text { due to voids } \\
\left(\mathrm{cm}^{3} \mathrm{~g}^{-1}\right)\end{array}$ \\
$\begin{array}{l}\text { Porous } \mathrm{Mg} \\
\text { scaffold }\end{array}$ & $26.05(1)$ & $39(5)$ & 0.06 & 0.77 & $\begin{array}{l}\text { Total pore } \\
\text { volume } \\
\left(\mathrm{cm}^{3} \mathrm{~g}^{-1}\right)\end{array}$ \\
\hline
\end{tabular}
scaffold 


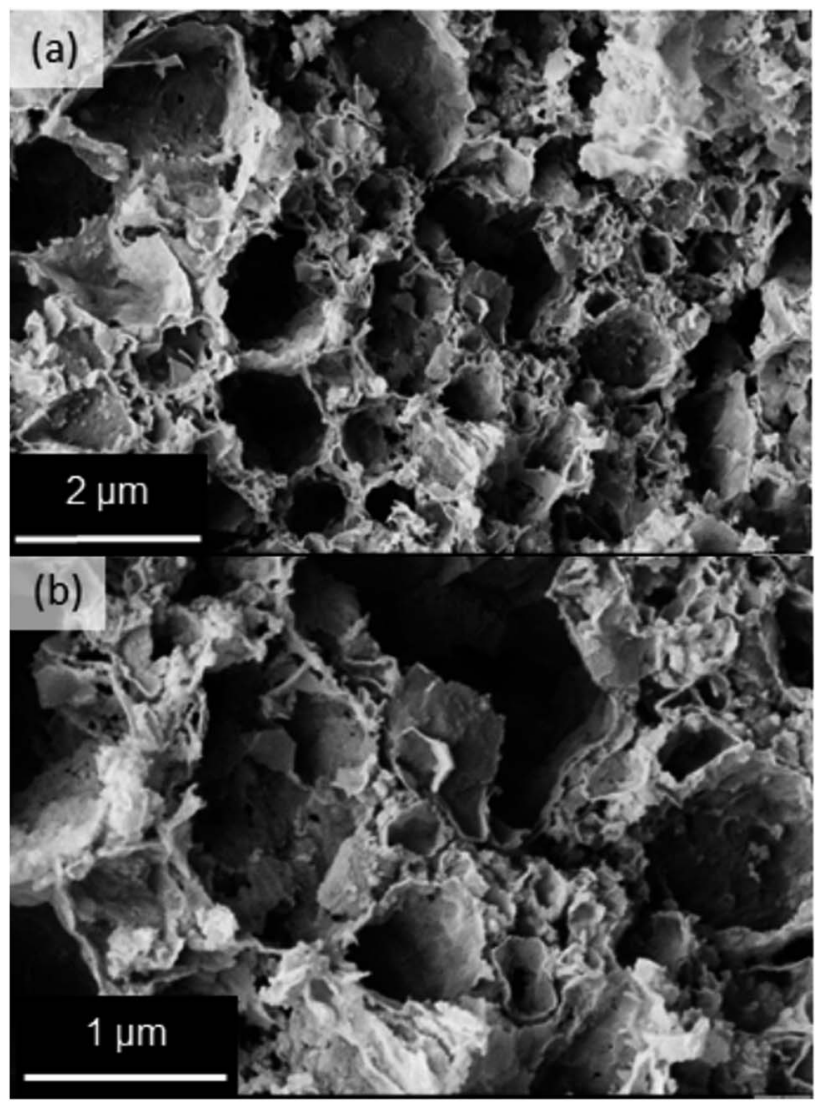

Fig. 6 SEM micrographs of the as-prepared porous Mg scaffold with two different magnifications (a) low and (b) high magnification.

first at lower temperatures compared to molten Na. Thus, once the $\mathrm{H}_{2}$ is desorbed from the main body of the pellet, the system has enough time to reform the pore structure as the final temperature has not been reached and the Na present is starting to become molten. Therefore, more sintering experiments with various $\mathrm{H}_{2}$ backpressures are required in order to investigate the formation of the pores. The delay of $\mathrm{H}_{2}$ desorption during the sintering of the $\mathrm{NaMgH}_{3}$ pellet will result in the presence of more mesopores present in the scaffold.

Fig. 7 shows the SEM micrographs of the porous $\mathrm{Mg}$ scaffolds infiltrated with $12.78,22.50$ and 32.55 wt\% of $\mathrm{LiBH}_{4}$ respectively. It is noticeable that the complex metal hydride first occupies the smaller pores (mesopores) via capillary condensation as seen in Fig. 6(a and b). As the amount of the infiltrated $\mathrm{LiBH}_{4}$ increases, the larger pores get occupied with the complex metal hydride (Fig. 7(c and d)). Lastly, Fig. 7(e and f) represents the porous $\mathrm{Mg}$ scaffold that has been infiltrated with the highest amount of $\mathrm{LiBH}_{4}$. It can be seen that the complex metal hydride has infiltrated all the pores present in the sample creating a solid pellet.

\subsection{Thermal analysis}

The TPD curves off the melt-infiltrated as well as the bulk samples are presented in Fig. 8 and 9. In Fig. 8(b) and 9(b) the $\mathrm{H}_{2}$ wt $\%$ has been normalised to the amount of desorbed $\mathrm{H}_{2}$ for each sample in order for results to be easily comparable. In Fig. 8(a) it is noticeable that the samples PMg13, PMg23 and PMg33 start desorbing $\mathrm{H}_{2}$ at $100{ }^{\circ} \mathrm{C}$. According to our knowledge, such, a result has not be reported in the literature so far. There is no $\mathrm{H}_{2}$ desorption detected for the bulk samples at that temperature range (Bulk $\mathrm{LiBH}_{4}$, Bulk pellet, Bulk powder, Bulk $2 \mathrm{LiBH}_{4}: \mathrm{Mg}$ ). This behaviour is attributed to the $\mathrm{LiBH}_{4}$ meltinfiltrated into the mesopores of the $\mathrm{Mg}$ scaffold. The infiltrated complex metal hydride in the pores is not only nanoconfined, but also destabilised by the presence of the $\mathrm{Mg}$ and $\mathrm{MgH}_{2}$. The volume created by the mesopores in each sample is the same. Thus, the amount of the desorbed $\mathrm{H}_{2}$ in all three samples at the temperature range of 100 to $420{ }^{\circ} \mathrm{C}$ is the same (Fig. 8(a)). As the temperature increases, it can be seen that PMg23 and PMg33 have the same desorption profiles as the

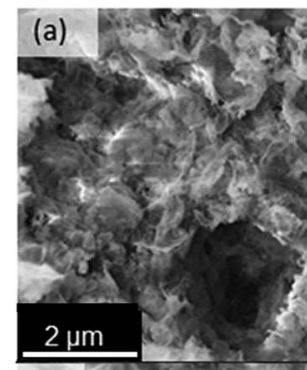

(b)

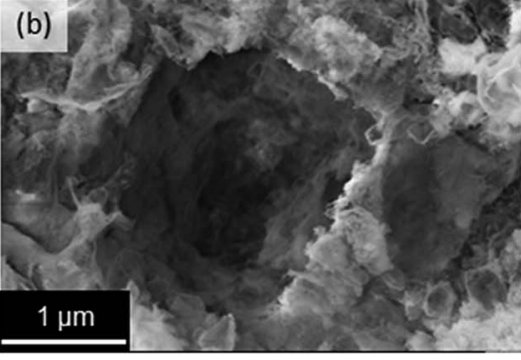

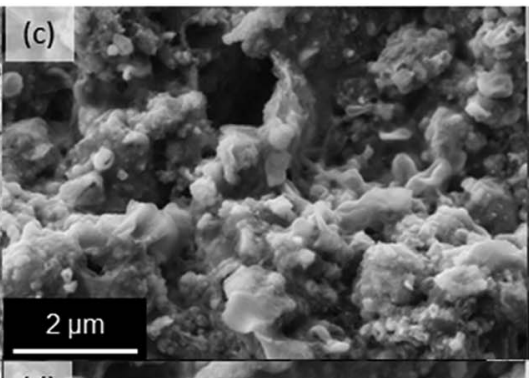

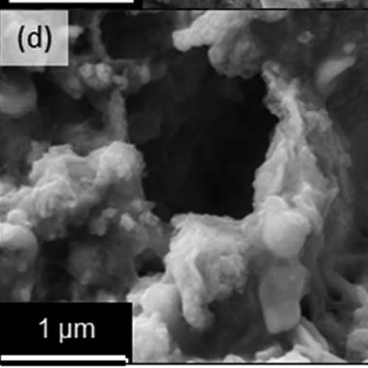

(e)

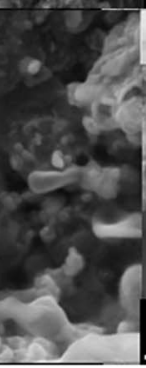

(f)
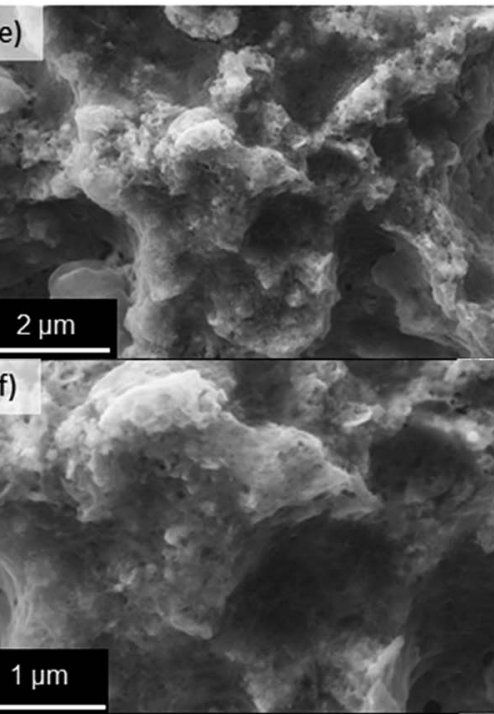

Fig. 7 SEM micrographs of the (a, b) PMg13, (c, d) PMg23 and (e, f) PMg33. 

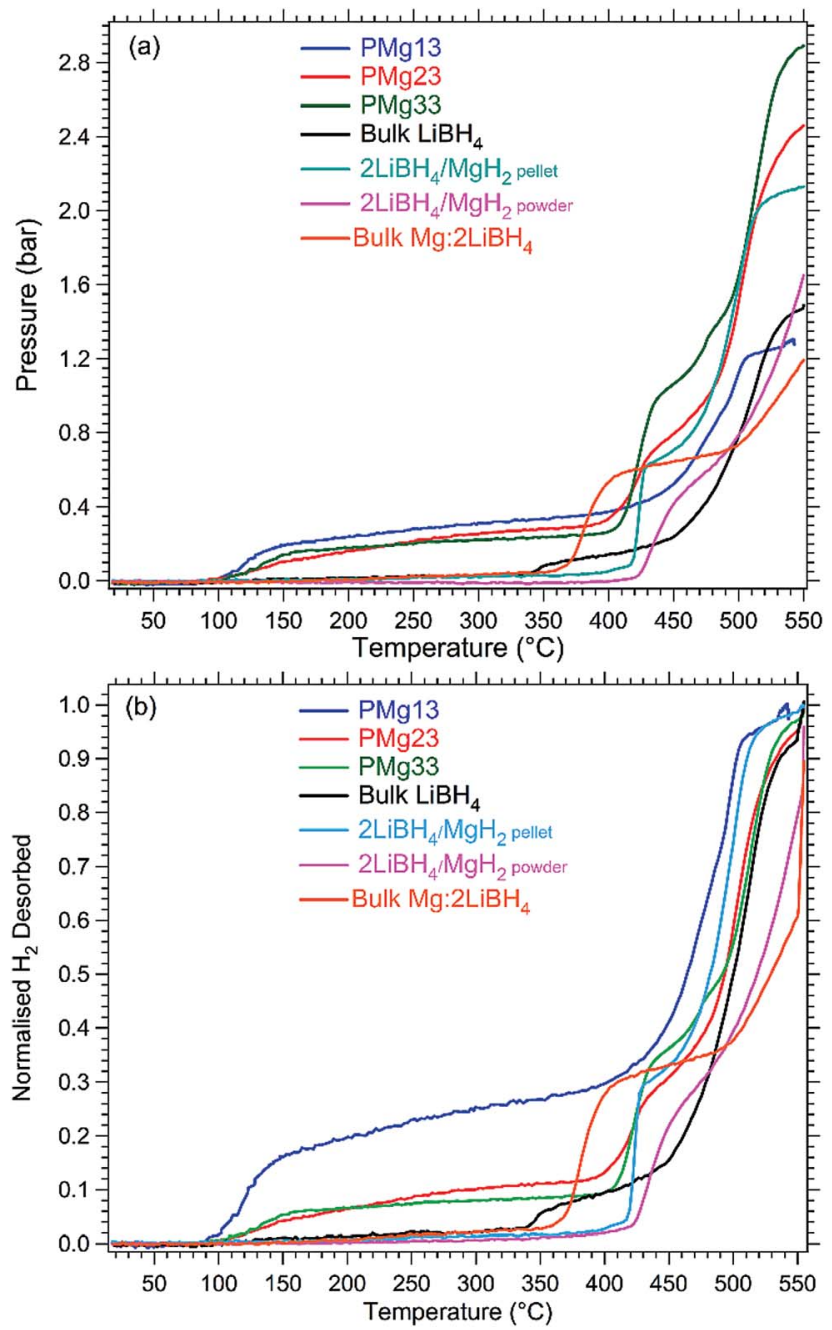

Fig. 8 Temperature programmed desorption results for PMg13, PMg23, PMg33, bulk $\mathrm{LiBH}_{4}$, bulk $2 \mathrm{LiBH}_{4} / \mathrm{MgH}_{2}$ in a pellet form, bulk $2 \mathrm{LiBH}_{4} / \mathrm{MgH}_{2}$ in a powder form and bulk $\mathrm{Mg} / 2 \mathrm{LiBH} \mathrm{H}_{4}$ (a) desorbed hydrogen pressure versus temperature (b) normalised wt\% of hydrogen desorbed versus temperature.

bulk samples. This observation is due to the fact that once the infiltrated $\mathrm{LiBH}_{4}$ for these samples has occupied all the mesopores, it then starts to enter the macropores and voids of the scaffold. Therefore, the complex metal hydride at these macro sizes behaves as a bulk material and has the same $\mathrm{H}_{2}$ desorption properties as the bulk samples. In contrast, the sample with the least amount of infiltrated $\mathrm{LiBH}_{4}$ (PMg13) has a different $\mathrm{H}_{2}$ desorption profile which is due to the fact that the amount of $\mathrm{LiBH}_{4}$ contained in that scaffold occupies only the pores in the mesoporous range. This particular sample has desorbed $35 \%$ of its $\mathrm{H}_{2}$ wt $\%$ at $400{ }^{\circ} \mathrm{C}$ whereas the bulk pellet and bulk powder at that temperature is 0 .

Moreover, bulk $\mathrm{LiBH}_{4}$ starts desorbing $\mathrm{H}_{2}$ after its melting point at $350{ }^{\circ} \mathrm{C}$ whereas when it is mixed with $\mathrm{MgH}_{2}$ the desorption takes place at $430{ }^{\circ} \mathrm{C}$. According to the literature at high temperatures and low pressures, $\mathrm{LiBH}_{4}$ and $\mathrm{MgH}_{2}$ simultaneously decompose and form $\mathrm{MgB}_{2} \cdot{ }^{16}$ Therefore, the decomposition of $\mathrm{LiBH}_{4}$ at $350{ }^{\circ} \mathrm{C}$ is inhibited and it only takes place at
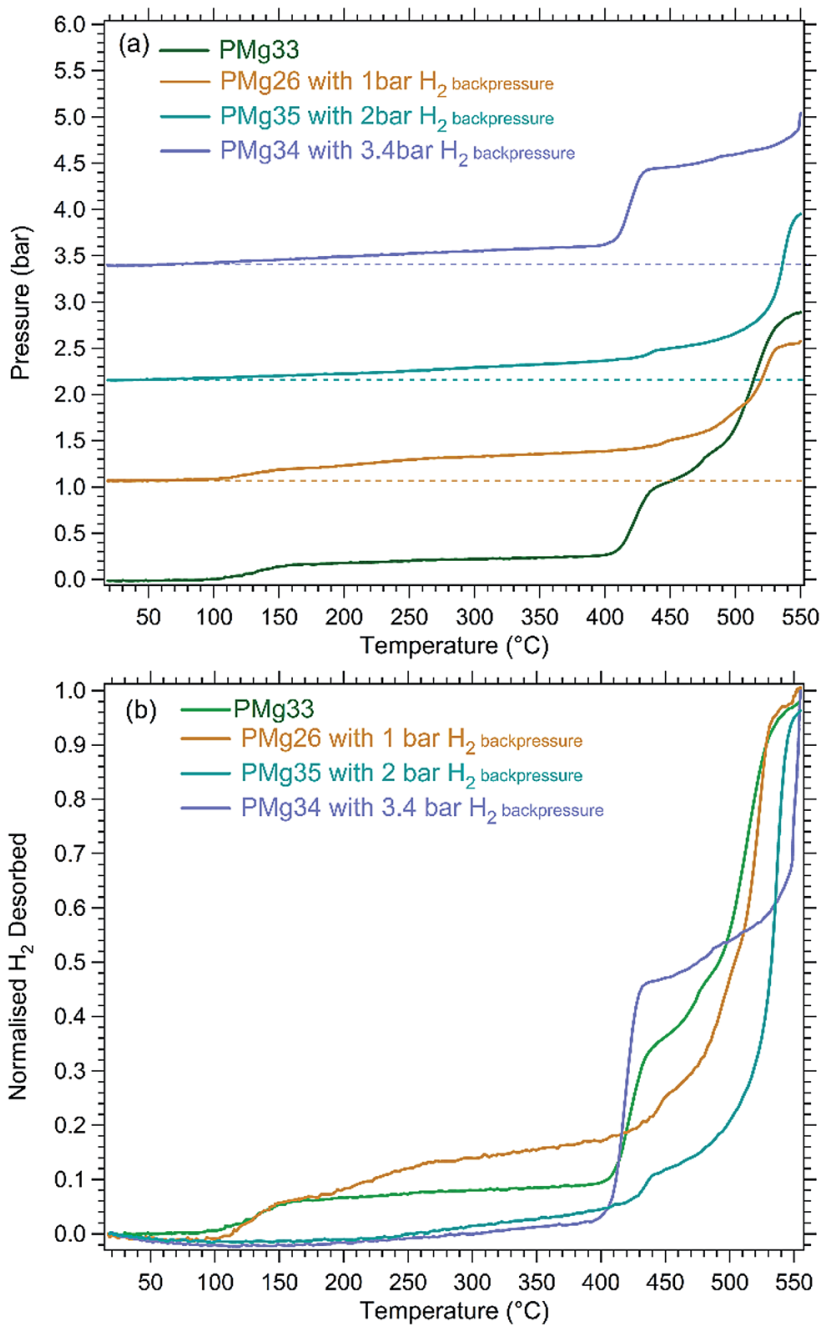

Fig. 9 Temperature programmed desorption results for PMg33, PMg26, PMg35 and PMg34 (a) desorbed hydrogen pressure versus temperature (b) normalised wt\% of hydrogen desorbed versus temperature conducted under $0,1,2$ and 3.4 bar of $\mathrm{H}_{2}$ backpressure.

higher temperatures. Lastly, bulk $\mathrm{Mg}: 2 \mathrm{LiBH}_{4}$ sample starts desorbing $\mathrm{H}_{2}$ at $350{ }^{\circ} \mathrm{C}$ similar to bulk $\mathrm{LiBH}_{4}$. As there is no $\mathrm{MgH}_{2}$ present in this sample, $\mathrm{MgB}_{2}$ is formed simultaneously when $\mathrm{LiBH}_{4}$ starts to decompose. Hence, the temperature for this reaction is at $350{ }^{\circ} \mathrm{C}$, as for bulk $\mathrm{LiBH}_{4}$.

Fig. 10 shows the experimental, as well as the theoretical, $\mathrm{H}_{2}$ $\mathrm{wt} \%$ of all samples that have been desorbed up to $550{ }^{\circ} \mathrm{C}$. For the samples for which the desorption started at 0 bar of $\mathrm{H}_{2}$ backpressure, the experimental and theoretical values are the same, taking into account the further decomposition of $\mathrm{LiH}$ (eqn (8)).

$$
\mathrm{LiH}+\mathrm{Mg} \rightarrow \mathrm{LiMg}+\frac{1}{2} \mathrm{H}_{2}
$$

LiH can further decompose at temperatures above $500{ }^{\circ} \mathrm{C}$, as the presence of excess $\mathrm{Mg}$ present from the porous scaffold is able to further react with the LiH formed from the first decomposition pathway. These samples exhibited high 


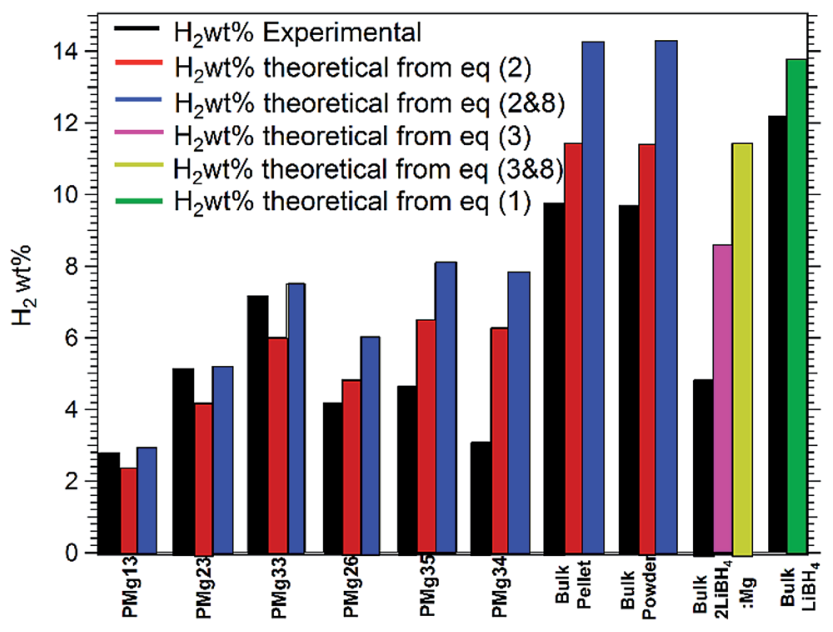

Fig. 10 Diagram representing the values of the theoretical as well as experimental $\mathrm{H}_{2}$ wt\% for all samples at $550{ }^{\circ} \mathrm{C}$.

desorbed $\mathrm{H}_{2}$ wt\% $\left(\mathrm{PMg} 23=5.09 \mathrm{H}_{2}\right.$ wt\%, PMg33 $=7.12 \mathrm{H}_{2}$ wt\%) reaching the targets set by the U.S. Department of Energy, ${ }^{6}$ which makes them promising candidates for on-board hydrogen storage in vehicles run by fuel cells.

The samples for which their decomposition took place under 1, 2, and 3.4 bar of $\mathrm{H}_{2}$ backpressure, the experimental value of the $\mathrm{H}_{2} \mathrm{wt} \%$ is smaller than the theoretical ones derived from eqn (2). The reason for this observation is due to the fact that the kinetics of this reaction slowed down as the $\mathrm{H}_{2}$ backpressure increased (Fig. S3†). Finally, the experimental desorbed $\mathrm{H}_{2}$ wt\% of all bulk samples are smaller than the theoretical ones as the formed agglomerations in the metal hydrides hindered the kinetics of the reaction and also the presence of $\mathrm{Mg}$ in the sample was not enough to further decompose the LiH. A table of all the values of the desorbed $\mathrm{H}_{2}$ $\mathrm{wt} \%$ as well as maximum pressures observed and temperatures are in Table $\mathrm{S} 1$ in the ESI. $\dagger$

In Fig. 11 the diffraction patterns of all samples after their TPD experiments are presented. All samples were crushed from a pellet to a powder in order to obtain a more comprehensive phase analysis from the entire sample. The diffraction patterns of the PMg13 and PMg23 (Fig. 8(a and b)) show only diffraction peaks corresponding to $\mathrm{Mg}, \mathrm{MgO}, \mathrm{MgB}_{2}$, and $\mathrm{LiMg}$. The $\mathrm{H}_{2}$ has been completely desorbed and no evidence of LiH, or partially unreacted $\mathrm{MgH}_{2}$ is present in the sample. These observations also confirm the value of the calculated experimental $\mathrm{H}_{2} \mathrm{wt} \%$ which is due to eqn (2) and (3) and matches the theoretical $\mathrm{H}_{2}$ wt\% calculated for eqn (8). The diffraction pattern of PMg33 has $\mathrm{MgH}_{2}$ diffraction peaks, suggesting that during the cooling of the sample, a small amount of $\mathrm{H}_{2}$ was reabsorbed from the $\mathrm{Mg}$ scaffold to form $\mathrm{MgH}_{2}$. The experimental value of the desorbed $\mathrm{H}_{2}$ wt\% for this sample is slightly smaller than the theoretical one derived from eqn (6). This indicates that the $\mathrm{MgH}_{2}$ present in the sample should have been completely desorbed when the sample was reached $550{ }^{\circ} \mathrm{C}$ and the remaining $\mathrm{MgH}_{2}$ could only be formed during reabsorption while cooling down. The presence of $\mathrm{LiH}$ in this particular sample indicates that the further

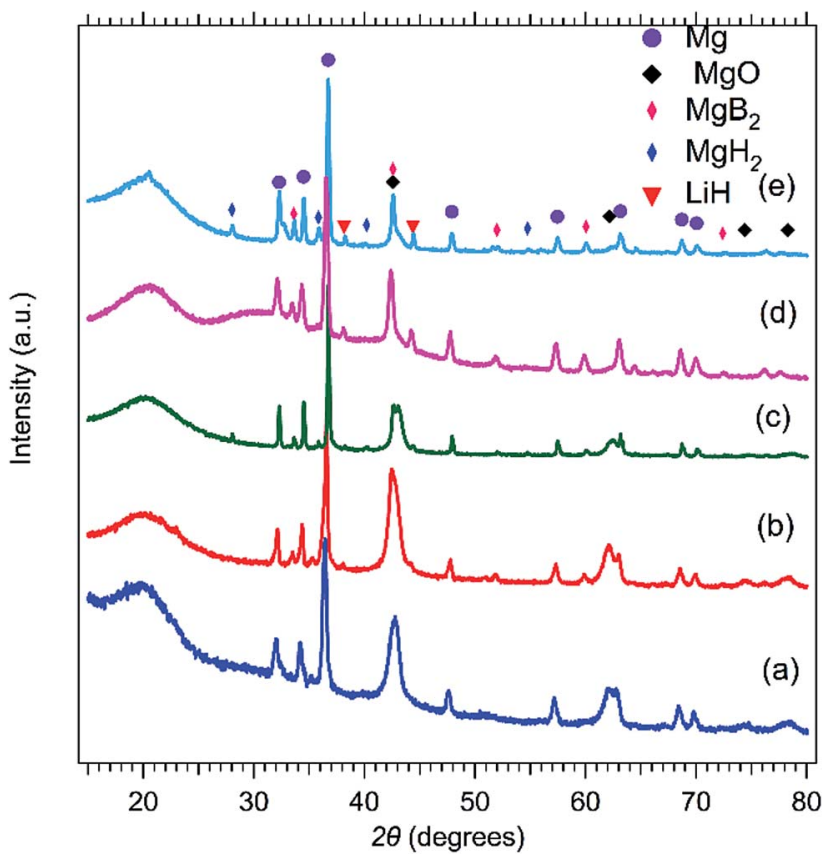

Fig. 11 XRD patterns of (a) PMg13, (b) PMg23, (c) PMg33 (d) bulk $2 \mathrm{LiBH}_{4} / \mathrm{MgH}_{2}$ in a form of a powder and (e) pellet after TPD experiments conducted under $\mathrm{O}$ bar of $\mathrm{H}_{2}$ backpressure.

decomposition of LiH was incomplete, which is indicative of the slight mismatch of the experimental and theoretical value (from eqn (6)) of desorbed $\mathrm{H}_{2} \mathrm{wt} \%$. The diffraction patterns of the bulk samples show both $\mathrm{MgH}_{2}$ and $\mathrm{LiH}$, which is due to the incomplete reaction of eqn (2), explains the lower experimental

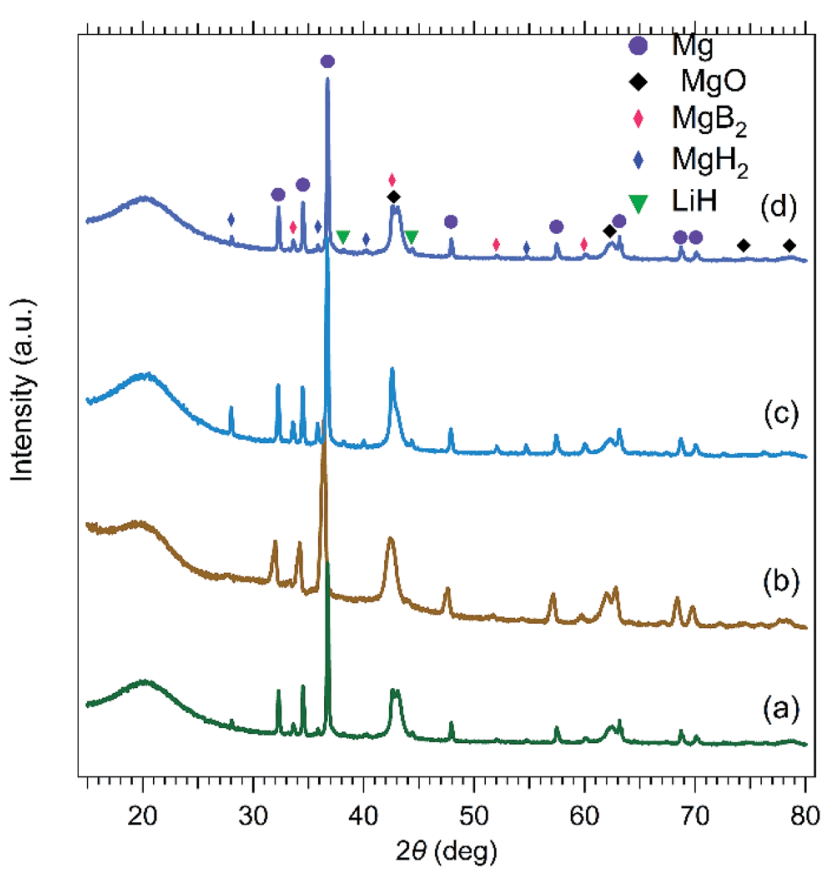

Fig. 12 XRD patterns of (a) PMg33, (b) PMg26, (c) PMg34 and (d) PMg35 after TPD experiments which were performed under 0, 1, 2 and 3.4 bar of $\mathrm{H}_{2}$ backpressure respectively. 
values of their desorbed $\mathrm{H}_{2} \mathrm{wt} \%$ in comparison to the theoretical values.

Fig. 12 shows the diffraction patterns of all samples that were infiltrated with the highest amount of $\mathrm{LiBH}_{4}$ and were desorbed under different values of $\mathrm{H}_{2}$ backpressures. For the samples PMg33 and PMg26, the amount of $\mathrm{LiH}$ present in the samples is almost undetectable due to the small amount of $\mathrm{LiH}$, as well as its low scattering power. The presence of $\mathrm{LiH}$ and $\mathrm{MgH}_{2}$ is more evident in the diffraction patterns of the samples PMg33 and PMg35 that were desorbed with starting $\mathrm{H}_{2}$ back pressures at 2 and 3.4 bar respectively. The kinetics of eqn (2) were slower in comparison to the ones of the samples that were desorbed at lower $\mathrm{H}_{2}$ backpressures ( 0 and 1 bar of $\mathrm{H}_{2}$ ) therefore the amount of $\mathrm{MgH}_{2}$ and $\mathrm{LiH}$ are higher and therefore easier to detect.

\section{Conclusion}

A porous $\mathrm{Mg}$ scaffold was synthesised using a cost effective method by sintering a $\mathrm{NaMgH}_{3}$ pellet under dynamic vacuum. The created scaffold consisted of pores in the meso and macro range as seen from SEM micrographs and the BJH analysis. The pores were created by the desorption of $\mathrm{H}_{2}$ and the evaporation of $\mathrm{Na}$. The diffraction pattern after the sintering, showed that the scaffold is composed of Mg. SEM micrographs, as well as diffraction analysis of the infiltrated samples confirmed that the $\mathrm{LiBH}_{4}$ entered the pores of the scaffold by first occupying the smaller pores, followed by the larger ones. The Temperature Programmed Desorption measurements of all samples showed that the infiltrated samples started desorbing $\mathrm{H}_{2}$ at $100{ }^{\circ} \mathrm{C}$ which is $250{ }^{\circ} \mathrm{C}$ lower than the accepted temperature the bulk $\mathrm{LiBH}_{4}$ and $330^{\circ} \mathrm{C}$ lower than the accepted temperature for bulk $2 \mathrm{LiBH}_{4}-\mathrm{MgH}_{2}$. PMg13 desorbed $35 \%$ of its total value of $\mathrm{H}_{2}$ below the melting point of $\mathrm{LiBH}_{4}\left(350{ }^{\circ} \mathrm{C}\right)$. The PMg33 sample exhibited enhanced hydrogen storage properties $\left(7.12 \mathrm{H}_{2} \mathrm{wt} \%\right)$ and exceeded the targets set by the U.S. Department of Energy (5.5 $\mathrm{H}_{2}$ wt\%). Further improvements have to be made regarding the synthesis process of the porous $\mathrm{Mg}$ scaffold in order to increase the number of mesopores. This will allow the $\mathrm{LiBH}_{4}$ melt-infiltrated samples to not only desorb $\mathrm{H}_{2}$ at $100{ }^{\circ} \mathrm{C}$ or less, but also to reach and hopefully exceed the $5.5 \mathrm{H}_{2} \mathrm{wt} \%$ target, making them ideal candidates for on-board hydrogen storage in automobile applications. Lastly, the reversibility of the $\mathrm{LiBH}_{4}$ melt-infiltrated samples needs to be investigated by rehydrogenating the samples under various $\mathrm{H}_{2}$ backpressures and temperatures.

\section{Acknowledgements}

The authors CEB, DAS and MVS acknowledge the financial support of the Australian Research Council for ARC Discovery grant DP150101708. The author DAS acknowledge the financial support of a Curtin University's Postdoctoral Research Fellowship. The authors acknowledge the facilities and technical assistance of the Microscopy \& Microanalysis Facility of the John de Laeter Centre at Curtin University. CEB acknowledges the financial support of the Australian Research Council for
ARC LIEF grants LE0775551 and LE0989180 which enabled the XRD and TPD measurements to be undertaken. The authors would like to thank the project team of the Small Angle X-ray Scattering at the Australian Synchrotron.

\section{References}

1 L. Schlapbach and A. Züttel, Nature, 2001, 414, 353-358.

2 A. Züttel, A. Remhof, A. Borgschulte and O. Friedrichs, Philos. Trans. R. Soc., A, 2010, 368, 3329-3342.

3 K. Hirose, Philos. Trans. R. Soc., A, 2010, 368, 3365-3377.

4 M. B. Ley, L. H. Jepsen, Y.-S. Lee, Y. W. Cho, J. M. Bellosta von Colbe, M. Dornheim, M. Rokni, J. O. Jensen, M. Sloth, Y. Filinchuk, J. E. Jørgensen, F. Besenbacher and T. R. Jensen, Mater. Today, 2014, 17, 122-128.

5 M. Meggouh, D. M. Grant and G. S. Walker, J. Phys. Chem. C, 2011, 115, 22054-22061.

6 Energy.Gov, Office of Energy Efficiency \& Renewable Energy, http://energy.gov/eere/fuelcells/hydrogen-storage, accessed 13/7/2016.

7 A. Züttel, P. Wenger, S. Rentsch, P. Sudan, P. Mauron and C. Emmenegger, J. Power Sources, 2003, 118, 1-7.

8 S. Cahen, J. B. Eymery, R. Janot and J. M. Tarascon, J. Power Sources, 2009, 189, 902-908.

9 J. J. Vajo, F. Mertens, C. C. Ahn, R. C. Bowman and B. Fultz, J. Phys. Chem. B, 2004, 108, 13977-13983.

10 J. Yang, A. Sudik and C. Wolverton, J. Phys. Chem. C, 2007, 111, 19134-19140.

11 S.-A. Jin, J.-H. Shim, Y. W. Cho, K.-W. Yi, O. Zabara and M. Fichtner, Scr. Mater., 2008, 58, 963-965.

12 U. Bösenberg, S. Doppiu, L. Mosegaard, G. Barkhordarian, N. Eigen, A. Borgschulte, T. R. Jensen, Y. Cerenius, O. Gutfleisch, T. Klassen, M. Dornheim and R. Bormann, Acta Mater., 2007, 55, 3951-3958.

13 J. J. Vajo and G. L. Olson, Scr. Mater., 2007, 56, 829-834.

14 J. A. Puszkiel and F. C. Gennari, Scr. Mater., 2009, 60, 667670.

15 J. J. Vajo, S. L. Skeith and F. Mertens, J. Phys. Chem. B, 2005, 109, 3719-3722.

16 U. Bösenberg, D. B. Ravnsbæk, H. Hagemann, V. D'Anna, C. B. Minella, C. Pistidda, W. van Beek, T. R. Jensen, R. Bormann and M. Dornheim, J. Phys. Chem. C, 2010, 114, 15212-15217.

17 T. E. Price, D. M. Grant, D. Weston, T. Hansen, L. M. Arnbjerg, D. B. Ravnsbaek, T. R. Jensen and G. S. Walker, J. Am. Chem. Soc., 2011, 133, 13534-13538.

18 J. F. Mao, Z. Wu, T. J. Chen, B. C. Weng, N. X. Xu, T. S. Huang, Z. P. Guo, H. K. Liu, D. M. Grant, G. S. Walker and X. B. Yu, J. Phys. Chem. C, 2007, 111, 12495-12498.

19 B. R. Hansen, D. B. Ravnsbaek, J. Skibsted and T. R. Jensen, Phys. Chem. Chem. Phys., 2014, 16, 8970-8980.

20 F. E. Pinkerton, M. S. Meyer, G. P. Meisner, M. P. Balogh and J. J. Vajo, J. Phys. Chem. C, 2007, 111, 12881-12885.

21 J. Puszkiel, F. C. Gennari, P. Arneodo Larochette, H. E. Troiani, F. Karimi, C. Pistidda, R. Gosalawit-Utke, J. Jepsen, T. R. Jensen, C. Gundlach, M. Tolkiehn, 
J. Bellosta von Colbe, T. Klassen and M. Dornheim, J. Power Sources, 2014, 267, 799-811.

22 R. Gosalawit-Utke, C. Milanese, T. K. Nielsen, F. Karimi, I. Saldan, K. Pranzas, T. R. Jensen, A. Marini, T. Klassen and M. Dornheim, Int. J. Hydrogen Energy, 2013, 38, 19321942.

23 R. Gosalawit-Utke, T. K. Nielsen, I. Saldan, D. Laipple, Y. Cerenius, T. R. Jensen, T. Klassen and M. Dornheim, J. Phys. Chem. C, 2011, 115, 10903-10910.

24 R. Gosalawit-Utke, T. K. Nielsen, K. Pranzas, I. Saldan, C. Pistidda, F. Karimi, D. Laipple, J. Skibsted, T. R. Jensen, T. Klassen and M. Dornheim, J. Phys. Chem. C, 2012, 116, 1526-1534.

25 R. Gosalawit-Utke, C. Milanese, P. Javadian, A. Girella, D. Laipple, J. Puszkiel, A. S. Cattaneo, C. Ferrara, J. Wittayakhun, J. Skibsted, T. R. Jensen, A. Marini, T. Klassen and M. Dornheim, J. Alloys Compd., 2014, 599, 78-86.

26 R. Gosalawit-Utke, C. Milanese, P. Javadian, J. Jepsen, D. Laipple, F. Karmi, J. Puszkiel, T. R. Jensen, A. Marini, T. Klassen and M. Dornheim, Int. J. Hydrogen Energy, 2013, 38, 3275-3282.

27 S. A. Al-Muhtaseb and J. A. Ritter, Adv. Mater., 2003, 15, 101114.

28 H. P. Boehm, Carbon, 1994, 32, 759-769.

29 R. Fu, B. Zheng, J. Liu, S. Weiss, J. Y. Ying, M. S. Dresselhaus, G. Dresselhaus, J. Satcher and T. Baumann, J. Appl. Polym. Sci., 2004, 91, 3060-3067.

30 Y. Bi, Y. Zheng and Y. Li, Mater. Lett., 2015, 161, 583-586.

31 J. J. de Damborenea, M. A. Larosa, M. A. Arenas, J. M. Hernández-López, A. L. Jardini, M. C. F. Ierardi, C. A. C. Zavaglia, R. M. Filho and A. Conde, Mater. Des., 2015, 83, 6-13.

32 L. H. S. Gasparotto, A. Prowald, N. Borisenko, S. Z. El Abedin, A. Garsuch and F. Endres, J. Power Sources, 2011, 196, 28792883.

33 M. V. Sofianos, D. A. Sheppard, E. Ianni, T. D. Humphries, M. R. Rowles, S. M. Liu and C. E. Buckley, J. Alloys Compd., 2017, 702, 309-317.

34 Y. Filinchuk, D. Chernyshov and R. Cerny, J. Phys. Chem. C, 2008, 112, 10579-10584.

35 R. W. G. Wyckoff, in Cubic closest packed, ccp, structure, Interscience Publishers, New York, 2nd edn, 1963, pp. 7-83.

36 S. Brunauer, P. H. Emmett and E. Teller, J. Am. Chem. Soc., 1938, 60, 309-319.

37 E. P. Barrett, L. G. Joyner and P. P. Halenda, J. Am. Chem. Soc., 1951, 73, 373-380.
38 O. Spalla, S. Lyonnard and F. Testard, J. Appl. Crystallogr., 2003, 36, 338-347.

39 G. Beaucage, J. Appl. Crystallogr., 1995, 28, 717-728.

40 J. Ilavsky and P. R. Jemian, J. Appl. Crystallogr., 2009, 42, 347353.

41 A. J. Hurd, D. W. Schaefer, D. M. Smith, S. B. Ross, A. Le Méhauté and S. Spooner, Phys. Rev. B: Condens. Matter Mater. Phys., 1989, 39, 9742-9745.

42 G. Beaucage, J. Appl. Crystallogr., 1996, 29, 134-146.

43 A.-L. Chaudhary, M. Paskevicius, D. A. Sheppard and C. E. Buckley, J. Alloys Compd., 2015, 623, 109-116.

44 D. A. Sheppard, M. Paskevicius and C. E. Buckley, Chem. Mater., 2011, 23, 4298-4300.

45 K. Ikeda, Y. Kogure, Y. Nakamori and S. Orimo, Scr. Mater., 2005, 53, 319-322.

46 H. Reardon, N. Mazur and D. H. Gregory, Prog. Nat. Sci.: Mater. Int., 2013, 23, 343-350.

47 S. Abdessameud, M. Mezbahul-Islam and M. Medraj, Sci. World J., 2014, 2014, 1-16.

48 D. Pottmaier, E. R. Pinatel, J. G. Vitillo, S. Garroni, M. Orlova, M. D. Baró, G. B. M. Vaughan, M. Fichtner, W. Lohstroh and M. Baricco, Chem. Mater., 2011, 23, 2317-2326.

49 C. P. Balde, H. A. Stil, A. M. J. vanderEerden, K. P. deJong and J. H. Bitter, J. Phys. Chem. C, 2007, 111, 2797-2802.

50 M. Felderhoff, K. Klementiev, W. Grünert, B. Spliethoff, B. Tesche, J. M. Bellosta von Colbe, B. Bogdanovi, M. Hrtel, A. Pommerin, F. Schüth and C. Weidenthaler, Phys. Chem. Chem. Phys., 2004, 6, 4369-4374.

51 A. G. Haiduc, H. A. Stil, M. A. Schwarz, P. Paulus and J. J. C. Geerlings, J. Alloys Compd., 2005, 393, 252-263.

52 T. D. Humphries, D. Birkmire, B. C. Hauback, G. S. McGrady and C. M. Jensen, Phys. Chem. Chem. Phys., 2013, 15, 61796181.

53 T. D. Humphries, J. W. Makepeace, S. Hino, W. I. F. David and B. C. Hauback, J. Mater. Chem. A, 2014, 2, 16594-16600.

54 D. M. Banus, J. J. McSharry and E. A. Sullivan, J. Am. Chem. Soc., 1955, 77, 2007-2010.

55 W. Klostermeier and E. U. Franck, Ber. Bunsenges. Phys. Chem., 1982, 86, 606-612.

56 B. Bogdanović, H. Hofmann, A. Neuy, A. Reiser, K. Schlichte, B. Spliethoff and S. Wessel, J. Alloys Compd., 1999, 292, 5771.

57 N. Bernstein, M. D. Johannes and K. Hoang, Phys. Rev. B: Condens. Matter Mater. Phys., 2013, 88, 2201021-2201025.

58 L. Shaohua, B. Jingru, L. Hongpeng, J. Guojun and W. Qing, Oil Shale, 2010, 27, 135. 